\title{
Current and former smokers among adolescents aged $12-17$ years in Iran: a systematic review and meta-analysis
}

\author{
Elham Ehsani-Chimeh ${ }^{1}$, Haniye Sadat Sajadi ${ }^{1}$, Meysam Behzadifar ${ }^{2}$, Maryam Aghaei $^{3}$, Afsaneh Badrizadeh ${ }^{4}$, \\ Masoud Behzadifar ${ }^{4 *}$ (D) and Nicola Luigi Bragazzi ${ }^{5,6}$
}

\begin{abstract}
Background: Smoking, especially among adolescents, is considered a serious public health concern worldwide being associated with increased mortality. The present study was designed as the first systematic review and metaanalysis of the prevalence of current and former smoking behavior among adolescents in Iran.

Methods: Seven international scholarly databases, namely Scopus, Embase, Pubmed/Medline, ISI/Web of Science (WOS), the Cochrane Library, Psyc Info and Cinahl, were extensively searched from January 2000 to September 18, 2019. Google Scholar was also mined. Iranian databases were searched as well (namely, Maglran, Scientific Information Database (SID), and Barakatkns). The DerSimonian-Laird's approach, via the Freeman-Tukey double arcsine method, was used to synthesize the prevalence estimates.

Results: The prevalence of current smokers among Iranian adolescents was estimated to be $9 \%$ (95\% Cl: 7 to 10). Stratifying based on gender, the prevalence was $12 \%$ among boys (95\% Cl: 10 to 14) and 6\% among girls (95\% Cl: 5 to 8). The prevalence of former smokers among Iranian adolescents using the random-effect model was computed to be $24 \%$ (95\% Cl: 21 to 27 ).

Conclusion: The findings of this study showed that the prevalence of current and former smoking behavior among Iranian adolescents is a relevant public health concern. The country's young population should be given more attention by health policy- and decision-makers and implementation of ad hoc prevention and control policies should be on their agenda.
\end{abstract}

Keywords: Smoking behavior, Adolescents, Iran, Systematic review, Meta-analysis

\section{Background}

Smoking is considered as a serious public health concern worldwide and many healthcare planners are making serious efforts in order to reduce cigarette consumption by designing and implementing appropriate strategies in order to control one of the most important factors associated with increased mortality $[1,2]$. Smoking leads, indeed, to a higher risk of cardiovascular disease, lung disorders as well as several malignancies, including lung, throat, stomach, and bladder cancers [3].

\footnotetext{
* Correspondence: masoudbehzadifar@gmail.com

${ }^{4}$ Social Determinants of Health Research Center, Lorestan University of Medical Sciences, Khorramabad, Iran

Full list of author information is available at the end of the article
}

In 2010, smoking accounted for up to $6.3 \%$ of the global burden of disease [4]. In recent decades, smoking has been on the rise in developing countries, and, only after adopting appropriate policies, it has begun to slightly decline $[5,6]$. The World Health Organization (WHO) has computed that approximately 7 million smokers die each year because of smoking and 1.2 million die from passive cigarette exposure [7].

Adolescents as one of the high-risk groups starting to smoke are a very important age group and special attention should be paid to their behaviors from health policy- and decision-makers [8]. Early identifying smokers in this group and the associated determinants of smoking behavior can help reduce or stop cigarette consumption [9]. Also, controlling and preventing smoking can

(c) The Author(s). 2020 Open Access This article is distributed under the terms of the Creative Commons Attribution 4.0 International License (http://creativecommons.org/licenses/by/4.0/), which permits unrestricted use, distribution, and 
moderate other high-risk behaviors associated with a highrisk personality, such as alcohol use, unsafe sex $[10,11]$ and drug use [12]. There are several factors that influence smoking in this age group. Parental smoking, economic, social and cultural status, psychological factors such as parental divorce, and gender are among the major determinants [13]. Smoking and socializing with smokers are also some of the factors that make adolescents more likely to continue smoking [14].

Iran is one of the countries characterized by a young population. It is important for health planners to monitor their behaviors and try to keep cigarette consumption low among this age group, implementing ad hoc prevention and control programs if needed. Short- and long-term tobacco control plans can have many potential benefits in terms of health.

In recent years, several studies have been conducted on the prevalence of current and former smoking behavior among Iranian adolescents. Updated information can be used as valuable evidence for tobacco-related policies as well as for future chronic disease burden calculation. Health managers and decision-makers can rely on comprehensive reviews to design policies to prevent and control smoking among adolescents. To the best of our knowledge, there exists no a comprehensive synthesis of cigarette consumption rate in Iran. Therefore, the present study was designed as the first systematic review and meta-analysis of the prevalence of current and former smokers in this age group in Iran, in order to fill this gap in knowledge.

\section{Methods}

\section{Literature search and review}

Seven international scholarly databases, namely Scopus, Embase, Pubmed/Medline, ISI/Web of Science (WOS), the Cochrane Library, PsycInfo and Cinahl, were extensively searched from January 2000 to September 18, 2019. Google Scholar was also mined to increase the chance of finding potentially relevant studies related to the topic under scrutiny.

Iranian databases were searched as well (namely, MagIran, Scientific Information Database (SID), and Barakatkns). To systematically retrieve articles on cigarette consumption among Iranian adolescents, a string of keywords was used in the English or Farsi languages: Boolean operators (OR, AND, NOT) were used to properly connect the various terms. In particular, the search strategy was the following: Iran AND (tobacco OR cigarette OR cigarettes OR smoke OR "smoking behavior" OR "smoking") AND (youth OR adolescent OR adolescents OR student OR students) AND (epidemiology OR frequency OR rate OR prevalence OR use). The reference list of potentially relevant studies was also scanned for cross-referencing purpose.
Two authors independently conducted the literature search and review. The disagreement between them was resolved involving a third author, if necessary, or through discussion until agreement was achieved.

\section{Primary outcomes}

The primary outcomes of the present systematic review and meta-analysis were: i) the prevalence of current smokers, ii) the prevalence of former smokers, and, iii) the determinants of smoking behavior. The following definitions were adopted: a smoker was considered a current or former smoker if is smoking daily or if has quit smoking in the past 30 days.

\section{Inclusion and exclusion criteria}

Studies with the following characteristics were selected if: i) published in the English or Farsi languages, ii) conducted in the period 2000 to September 2019, iii) published in peer-reviewed journals, iv) providing sufficient data to calculate the prevalence of current and former smokers among Iranian adolescents aged 12-17 years, v) designed as cross-sectional investigations, and vi) questionnaire-based.

The following studies were excluded if: i) conducted before 2000, ii) not available as full-text, iii) not been peer-reviewed and published as abstract/conference proceedings, iv) lacking quantitative details, v) utilizing small sample sizes (less than 50 participants), vi) exploring the use of electronic cigarettes, vii) designed as casereports, case-series, case-control or randomized clinical trials (RCTs), and viii) not being conducted in Iran.

Two authors independently selected studies based on the above-mentioned inclusion and exclusion criteria.

\section{Data extraction}

The relevant data extracted included: surname of the first author, year of publication, country area/province of the study, sample size, mean age of participants, tool used to investigate current and former cigarette consumption, prevalence reported in the study, gender, study design, and determinants of smoking behavior. Two authors independently extracted the data utilizing an ad hoc designed, structured Excel spreadsheet. The disagreement between the two authors regarding the data extraction process was resolved through discussion.

\section{Methodological quality assessment}

The Joanna Briggs Institute (JBI) checklist for analytical cross-sectional studies was used to critically evaluate the quality of the methodology of the selected studies [15]. This checklist contains 8 questions with four possible replies ("yes", "no", "unclear", "not applicable"), exploring if: i) inclusion criteria are well defined, ii) study subjects and the setting are clearly described in detail, iii) 
exposure is measured in a valid, standardized, reliable way, iv) the condition is measured in an objective, standardized fashion, v) confounding factors are clearly identified and vi) properly corrected/adjusted for, with strategies clearly stated, vii) outcomes are properly measured, and viii) statistical analyses used are appropriate.

The Cohen's Kappa coefficient was used for measuring the degree of disagreement between the two independent authors during all the steps of the systematic review (search literature, studies selection, data extraction and methodological quality assessment of the studies) [16].

\section{Statistical analysis}

The DerSimonian-Laird approach, via the FreemanTukey double arcsine method, was used in order to estimate the pooled prevalence of current and former smokers among Iranian adolescents [17]. All synthesized estimates were reported with their computed 95\% confidence interval (CI). $p$-value $<0.05$ was considered significant. Initially, a preliminary analysis was performed and if heterogeneity among studies was over $50 \%$ a randomeffect model was preferred to a fixed-effect model to analyze all the data. In more detail, the $\mathrm{I}^{2}$ statistic was used to evaluate the amount of heterogeneity [18], which, depending on the $\mathrm{I}^{2}$ value, was stratified into low (25\%), moderate $(50 \%)$ and high $(75 \%)$. Publication bias was assessed inspecting the funnel plot in terms of asymmetry and using the Egger's linear regression test [19]. Sensitivity analysis was conducted to evaluate the data stability. The odds ratio (OR) was computed to compare the risk of smoking behavior based on the gender. Subgroup-analysis was performed to investigate possible sources of heterogeneity. For each moderator variable, a meta-regression analysis was also carried out according to the year of data collection and sample size to estimate their impact of the prevalence of current and former smokers. Data were analyzed using the STATA Ver.12 (Stata Corp, College Station, TX, USA) software.

\section{Results}

This study adhered to the "Preferred Reporting Items for Systematic Reviews and Meta-Analyses" (PRISMA) guidelines [20].

An initial literature search according to our search strategy resulted in a pool of 762 articles. We excluded 114 articles, because they were duplicate items. After scrutinizing

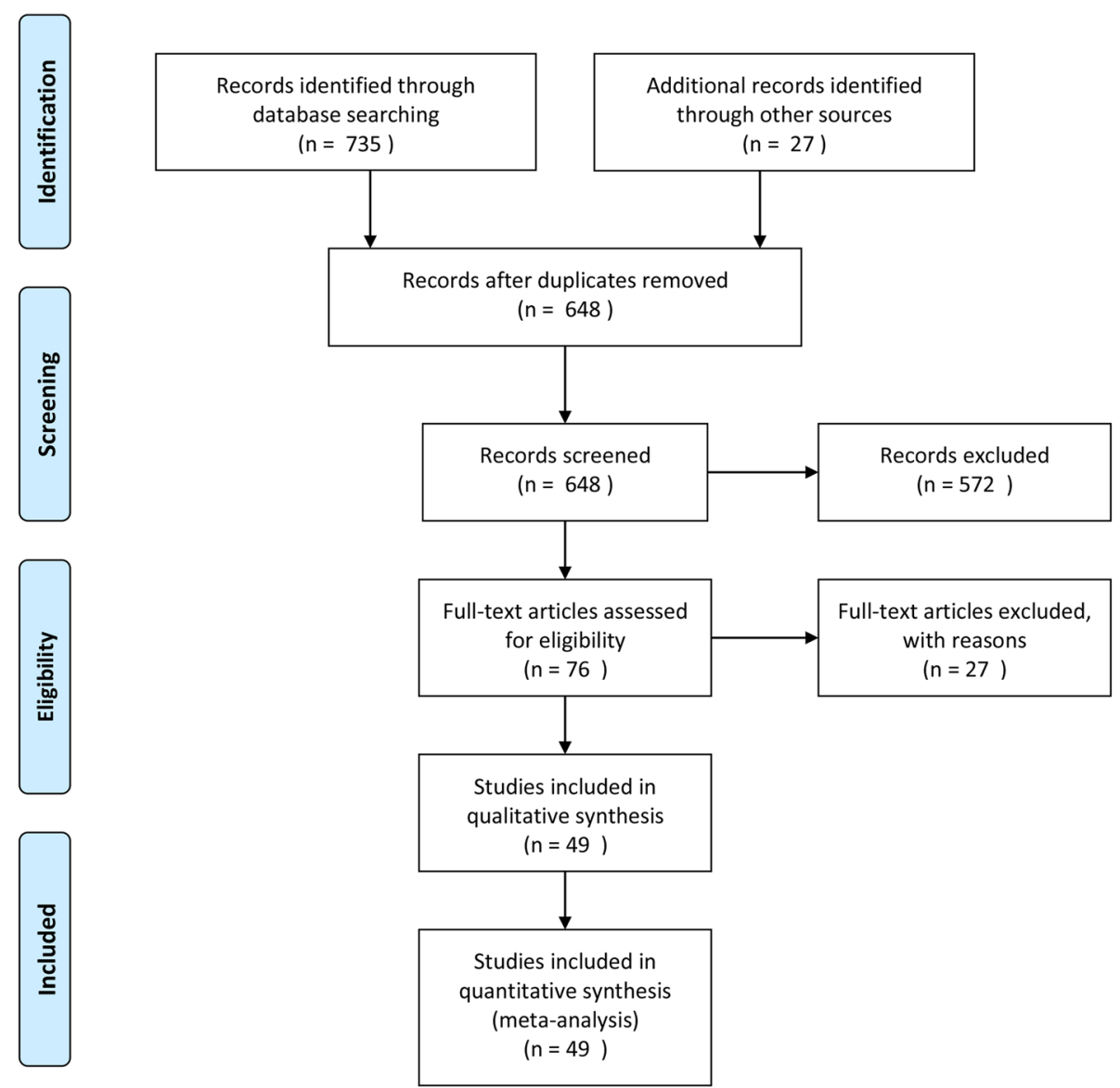

Fig. 1 Flow-chart showing the process of study retrieval, selection and inclusion adopted in the present systematic review and meta-analysis 
Table 1 Characteristics of included studies

\begin{tabular}{|c|c|c|c|c|c|c|c|c|c|}
\hline First author & Year & City & Mean age \pm SD & Sample size & No.boy & No. girl & Tools & Geographical area & $\begin{array}{l}\text { Where adolescents } \\
\text { live (urban, rural) }\end{array}$ \\
\hline Ayatollahi & 2004 & Shiraz & $16 \pm 0.77$ & 1132 & 1132 & 0 & SRQ & East & Urban \\
\hline Kelishadi & 2004 & Isfahan & NA & 1950 & 946 & 1004 & SRQ & Central & Both \\
\hline Mojahed & 2004 & Zahedan & $15.9 \pm 1$ & 475 & 216 & 259 & SRQ & Central & Urban \\
\hline Najafi & 2005 & Rasht & NA & 1474 & 751 & 723 & SRQ & Central & Urban \\
\hline Vafaei & 2005 & Tabriz & NA & 1000 & NA & NA & SRQ & West & Urban \\
\hline Heydari & 2007 & Tehran & 16.7 & 1093 & 712 & 381 & GYTS & West & Urban \\
\hline Najafi & 2007 & Guilan & NA & 1927 & 1041 & 886 & SRQ & North & Urban \\
\hline Barikani & 2008 & Tehran & $14.8 \pm 1.4$ & 700 & 374 & 326 & SRQ & Central & Urban \\
\hline Namakin & 2008 & Birjand & $16.3 \pm 1.3$ & 1233 & 1233 & 0 & SRQ & Central & Urban \\
\hline Ziaaddini & 2008 & Kerman & NA & 860 & 346 & 514 & SRQ & East & Urban \\
\hline Mohtasham Amiri & 2009 & Rasht & $16.2 \pm 0.9$ & 1400 & 1400 & 0 & $\mathrm{SRQ}$ & North & Urban \\
\hline Charkazi & 2010 & Zahedan & $15.9 \pm 7$ & 380 & NA & NA & SRQ & Central & Urban \\
\hline Emami & 2010 & Tehran & $17.53 \pm 0.59$ & 4566 & 2069 & 2497 & SRQ & North & Urban \\
\hline Gharlipour Gharghani & 2010 & Shiraz & NA & 244 & 244 & 0 & SRQ & Central & Urban \\
\hline Grarmaroudi & 2010 & Tehran & 16 & 2400 & 1200 & 1200 & SRQ & North & Urban \\
\hline Moeini & 2010 & Malayer & NA & 900 & 900 & 0 & SRQ & West & Urban \\
\hline Mohammadpoorasl & 2010 & Tabriz & $16.28 \pm 0.87$ & 1785 & NA & NA & SRQ & West & Urban \\
\hline Pasharavesh & 2010 & Kermanshah & $16.36 \pm 1.17$ & 3150 & 0 & 3150 & GYTS & West & Urban \\
\hline Rahmanian & 2010 & Jahrom & NA & 1145 & 697 & 448 & SRQ & South & Both \\
\hline Ramezankhani & 2010 & Tehran & $14.69 \pm 2.09$ & 4523 & 2272 & 2251 & SRQ & Central & Urban \\
\hline Alaee & 2011 & Karaj & $16.5 \pm 1.299$ & 447 & 208 & 239 & GYTS & Central & Urban \\
\hline Hamidzade Arbaby & 2011 & Khalkhal & NA & 260 & 260 & 0 & SRQ & West & Urban \\
\hline Ghavidel & 2012 & Nazarabad & 17 & 400 & 204 & 196 & SRQ & North & Urban \\
\hline Mohammadkhani & 2012 & 10 provinces & NA & 2538 & 1283 & 1255 & SRQ & NA & Urban \\
\hline Heydari & 2013 & Tehran & NA & 1271 & 1271 & 0 & SRQ & Central & Urban \\
\hline Javadzade & 2013 & Isfahan & $17.72 \pm 0.62$ & 382 & 382 & 0 & SRQ & Central & Urban \\
\hline Karimi & 2013 & Zarandieh & $16.21 \pm 1.45$ & 250 & 250 & 0 & SRQ & East & Urban \\
\hline Nazarzadeh & 2013 & Zanjan & $17.2 \pm 1.3$ & 352 & 352 & 0 & SRQ & East & Urban \\
\hline Barati & 2014 & Hamadan & $16.42 \pm 0.89$ & 810 & 810 & 0 & SRQ & West & Urban \\
\hline Bidel & 2014 & Ilam & $16.2 \pm 0.5$ & 1000 & 1000 & 0 & SRQ & West & Urban \\
\hline Esmaielzadeh & 2014 & Qazvin & NA & 510 & 271 & 239 & SRQ & West & Urban \\
\hline Khajehdaluee & 2014 & Sarakhs & NA & 943 & 507 & 436 & SRQ & West & Both \\
\hline Miri & 2014 & Birjand & $17.024 \pm 0.89$ & 2371 & 2371 & 0 & SRQ & East & Urban \\
\hline Mohammadi & 2014 & Babolsar & $15.3 \pm 0.5$ & 450 & 450 & 0 & SRQ & North & Both \\
\hline Pirdehghan & 2014 & Yazd & $16.02 \pm 0.9$ & 460 & 273 & 187 & GYTS & East & Urban \\
\hline Chaman & 2015 & Shahroud & $16.5 \pm 1.1$ & 450 & 450 & 0 & SRQ & East & Urban \\
\hline Madani & 2015 & Bandar Abbas & $16 \pm 1.34$ & 2029 & 1009 & 1020 & SRQ & South & Urban \\
\hline Meysamie & 2015 & Tehran & 16.21 & 2877 & 1557 & 1320 & SRQ & Central & Urban \\
\hline Rashid & 2015 & Tehran & 16.5 & 1022 & 511 & 511 & SRQ & Central & Urban \\
\hline Kelishadi & 2016 & 30 provinces & $12.47 \pm 3.36$ & 13,486 & 6846 & 6640 & GSHS & NA & Both \\
\hline Khoramdad & 2016 & Shiraz & 17 & 750 & 569 & 181 & SQR & Central & Urban \\
\hline Fakharri & 2017 & Tabriz & NA & 1000 & 460 & 540 & MCMI-III & West & Urban \\
\hline Karimi & 2017 & Shiraz & $16.11 \pm 1.16$ & 842 & 842 & 0 & SRQ & Central & Urban \\
\hline
\end{tabular}


Table 1 Characteristics of included studies (Continued)

\begin{tabular}{llllllllll}
\hline First author & Year & City & Mean age \pm SD & Sample size & No.boy & No. girl & Tools & $\begin{array}{c}\text { Geographical area } \\
\text { Where adolescents } \\
\text { live (urban, rural) }\end{array}$ \\
\hline Mohamadzadeh & 2017 & llam & NA & 372 & 199 & 173 & SRQ & West & Urban \\
Mohammadi & 2017 & Marivan & $16.2 \pm 0.25$ & 470 & 470 & 0 & SRQ & West & Urban \\
Ataeiasl & 2018 & Tabriz & $15.48 \pm 0.50$ & 1133 & 567 & 566 & SRQ & West & Urban \\
Farshidi & 2018 & Bandar Abbas & $16.4 \pm 1.1$ & 422 & 422 & 0 & SRQ & South & Urban \\
Jamshidi & 2018 & Ahvaz & $16.56 \pm 15.02$ & 899 & 450 & 449 & SRQ & South & Urban \\
Ansari & 2019 & Zahedan & NA & 1094 & 613 & 481 & SRQ & East & Urban
\end{tabular}

Global youth tobacco survey (GYTS), Self-report questionnaire (SRQ), Global School-based Student Health Survey (GSHS), Millon Clinical Multiaxial Inventory (MCMIIII), Not available (NA)

the titles and/or abstracts, 572 articles were excluded. The full text of 76 articles was screened in-depth and, finally, according to the previously mentioned inclusion and exclusion criteria, 49 articles were retained in the present systematic review and meta-analysis [21-69]. The entire process of study retrieval and selection is pictorially shown in Fig. 1.

The included studies were conducted between 2004 and 2019 , investigating a total sample of 71,859 Iranian adolescents. All the selected studies were cross-sectional investigations. The main characteristics of the selected studies are shown in Table 1, whereas the results of their methodological quality assessment are reported in Table 2 .

\section{Current cigarette smokers \\ The prevalence of current smokers}

Forty-one studies reported participants' current smoking status. The overall prevalence of current smokers among Iranian adolescents was estimated to be 9\% (95\% CI: 7 to 10$)$ with a highly, statistically significant heterogeneity $\left(\mathrm{I}^{2}=98.58 \%\right)$. (Fig. 2). Stratifying based on gender, the prevalence was $12 \%$ among boys (95\% CI: 10 to 14) and 6\% among girls (95\% CI: 5 to 8) (Appendix 1).

Sensitivity analysis was performed, and the results did not change before and after the analysis, indicating consistent results. There was no evidence of publication bias according to the visual inspection of the funnel plot and the Egger's linear regression test $(p=0.643)$.

Meta-regression was performed based on the year of data collection and sample size. The results showed that both these variables had no impact on the prevalence of current smokers among adolescents $(p=0.554$ and $p=$ 0.397, respectively) (Fig. 3 ).

The findings of the sub-group analyses based on gender and year of data collection are shown in Table 3. The prevalence among boys displayed a slightly increase throughout the time, whereas a slightly decreasing trend was found among girls. The prevalence of current smokers was higher in boys than girls. However, these findings should be interpreted with caution and only as suggestive of trends, in that: i) the sample sizes are relatively small, and ii) the $95 \%$ CIs are quite wide and partially overlapping.

Boys had a higher risk of being current smokers with respect to girls, with an OR of 2.77 (95\% CI: 2.17 to 3.53) (Fig. 4).

The prevalence of current smoking behavior stratified by geographical area and tool used is presented in Table 4, showing no effect of both variables.

Among the included studies, 16 studies recruited only boys and the prevalence of current smokers was estimated to be $9 \%$ (95\% CI: 6 to 11$)$ with $\mathrm{I}^{2}=97.6 \%$. Only the study by Pasharavesh et al. utilized a sample of girls [38]. A further 24 studies reported current smoking status in both genders and the prevalence of current smokers was estimated to be $8 \%$ ( $95 \%$ CI: 7 to 10 ) with $\mathrm{I}^{2}=98.8 \%$.

\section{Former cigarette smokers}

\section{The prevalence of former smokers}

40 studies reported participants' former smoking status. The prevalence of former smokers among Iranian adolescents using the random-effect model was computed to be $24 \%$ (95\% CI: 21 to 27$)$ with a high, statistically significant heterogeneity $\left(\mathrm{I}^{2}=99.15\right)$ (Fig. 5).

Publication bias visually inspecting the funnel plot and using the Egger's linear regression test was not detected $(p=0.12)$. Also, sensitivity analysis showed no changes before and after analysis and confirmed the consistency of results.

The prevalence of former smoking behavior among boys was $25 \%$ (95\% CI: 21 to 28), with an amount of heterogeneity of $\mathrm{I}^{2}=98.81 \%$, and among girls was $12 \%$ (95\% CI: 10 to 15$)$, with an amount of heterogeneity of $\mathrm{I}^{2}=$ 97.89\% (Appendix 2). Boys had a higher former smoking behavior risk with respect to boys, with an OR of 2.01 (95\% CI: 1.66 to 2.43) (Fig. 6).

Sub-analyses of prevalence of former smoking behavior stratified by gender and year of data collection are presented in Table 5.

Meta-regression was performed based on the year of data collection and sample size, showing no impact $(p=0.798$ and $p=0.281$, respectively) (Fig. 7). 
Table 2 Results of quality assessment

\begin{tabular}{|c|c|c|c|c|c|c|c|c|c|}
\hline First author & Year & Q1 & Q2 & Q3 & Q4 & Q5 & Q6 & Q7 & Q8 \\
\hline Ayatollahi & 2004 & Yes & No & Yes & No & Yes & Yes & Yes & Yes \\
\hline Kelishadi & 2004 & Yes & Yes & Yes & Yes & Yes & Yes & No & y \\
\hline Mojahed & 2004 & Yes & Yes & Yes & Yes & Yes & Yes & Yes & \\
\hline Najafi & 2005 & Yes & Yes & Yes & Yes & No & Yes & No & \\
\hline Vafaei & 2005 & Yes & No & Yes & Yes & Yes & Yes & Yes & \\
\hline Heydari & 2007 & Yes & Yes & No & Yes & Yes & Yes & Yes & \\
\hline Najafi & 2007 & Yes & No & Yes & Yes & No & Yes & Yes & \\
\hline Barikani & 2008 & Yes & Yes & Yes & Yes & Yes & No & Yes & \\
\hline Namakin & 2008 & Yes & Yes & Yes & Yes & Yes & Yes & Yes & \\
\hline Ziaaddini & 2008 & Yes & No & Yes & No & Yes & Yes & Yes & \\
\hline Mohtasham Amiri & 2009 & Yes & Yes & Yes & Yes & Yes & No & Yes & \\
\hline Charkazi & 2010 & Yes & No & Yes & Yes & Yes & Yes & Yes & \\
\hline Emami & 2010 & Yes & Yes & No & Yes & No & Yes & Yes & \\
\hline Gharlipour Gharghani & 2010 & Yes & No & Yes & Yes & Yes & Yes & No & \\
\hline Grarmaroudi & 2010 & Yes & Yes & Yes & Yes & Yes & No & Yes & \\
\hline Moeini & 2010 & Yes & No & Yes & Yes & No & Yes & Yes & \\
\hline Mohammadpoorasl & 2010 & Yes & Yes & Yes & Yes & Yes & Yes & No & \\
\hline Pasharavesh & 2010 & Yes & Yes & Yes & No & Yes & Yes & Yes & \\
\hline Rahmanian & 2010 & Yes & No & Yes & Yes & Yes & No & Yes & \\
\hline Ramezankhani & 2010 & Yes & No & No & Yes & Yes & Yes & Yes & \\
\hline Alaee & 2011 & Yes & Yes & Yes & Yes & Yes & Yes & Yes & \\
\hline Hamidzade Arbaby & 2011 & Yes & Yes & Yes & Yes & Yes & No & Yes & \\
\hline Ghavidel & 2012 & Yes & Yes & Yes & Yes & Yes & Yes & Yes & \\
\hline Mohammadkhani & 2012 & Yes & No & Yes & No & Yes & Yes & Yes & \\
\hline Heydari & 2013 & Yes & No & Yes & Yes & Yes & No & Yes & \\
\hline Javadzade & 2013 & Yes & Yes & Yes & Yes & Yes & Yes & No & \\
\hline Karimi & 2013 & Yes & Yes & Yes & Yes & Yes & Yes & Yes & \\
\hline Nazarzadeh & 2013 & Yes & Yes & Yes & No & Yes & Yes & Yes & \\
\hline Barati & 2014 & Yes & Yes & Yes & Yes & Yes & No & Yes & \\
\hline Bidel & 2014 & Yes & Yes & Yes & Yes & Yes & No & Yes & \\
\hline Esmaielzadeh & 2014 & Yes & No & Yes & Yes & No & Yes & Yes & \\
\hline Khajehdaluee & 2014 & Yes & No & Yes & Yes & Yes & Yes & Yes & \\
\hline Miri & 2014 & Yes & Yes & Yes & Yes & Yes & Yes & No & \\
\hline Mohammadi & 2014 & Yes & Yes & No & Yes & Yes & No & Yes & \\
\hline Pirdehghan & 2014 & Yes & Yes & Yes & Yes & Yes & Yes & Yes & \\
\hline Chaman & 2015 & Yes & Yes & Yes & No & Yes & Yes & Yes & \\
\hline Madani & 2015 & Yes & Yes & No & Yes & Yes & No & Yes & \\
\hline Meysamie & 2015 & Yes & Yes & Yes & Yes & Yes & Yes & No & \\
\hline Rashid & 2015 & Yes & Yes & Yes & Yes & No & Yes & Yes & \\
\hline Kelishadi & 2016 & Yes & Yes & Yes & No & Yes & Yes & No & \\
\hline Khoramdad & 2016 & Yes & Yes & Yes & Yes & Yes & No & Yes & \\
\hline Fakharri & 2017 & Yes & No & Yes & Yes & Yes & Yes & No & \\
\hline Karimi & 2017 & Yes & Yes & Yes & Yes & Yes & Yes & Yes & \\
\hline Mohamadzadeh & 2017 & Yes & Yes & Yes & Yes & Yes & Yes & Yes & \\
\hline
\end{tabular}

Table 2 Results of quality assessment (Continued)

\begin{tabular}{llllllllll}
\hline First author & Year & Q1 & Q2 & Q3 & Q4 & Q5 & Q6 & Q7 & Q8 \\
\hline Mohammadi & 2017 & Yes & Yes & No & Yes & Yes & Yes & No & Yes \\
Ataeiasl & 2018 & Yes & Yes & Yes & Yes & Yes & Yes & Yes & Yes \\
Farshidi & 2018 & Yes & Yes & Yes & Yes & Yes & Yes & No & Yes \\
Jamshidi & 2018 & Yes & Yes & Yes & Yes & No & Yes & Yes & Yes \\
Ansari & 2019 & Yes & No & Yes & Yes & Yes & Yes & No & Yes
\end{tabular}

(Q1: Were the criteria for inclusion in the sample clearly defined?, Q2: Were the study subjects and the setting described in detail?, Q3: Was the exposure measured in a valid and reliable way?, Q4: Were objective, standard criteria used for measurement of the condition?, Q5:Were confounding factors identified?, Q6: Were strategies to deal with confounding factors stated?, Q7: Were the outcomes measured in a valid and reliable way?, Q8: Was appropriate statistical analysis used?)

Among the included studies, 20 studies recruited only boys and the prevalence of former smokers was estimated to be $25 \%$ (95\% CI: 20 to 29 ) with $\mathrm{I}^{2}=99.3 \%$. Only the study of Pasharavesh et al. was conducted utilizing a sample of girls [38]. A further 19 studies reported former smoking status in both genders and the prevalence of former smokers was estimated to be $23 \%$ (95\% CI: 19 to 27 ) with $\mathrm{I}^{2}=98.3 \%$.

\section{Discussion}

The findings of the present study showed that the prevalence of current smoking behavior among Iranian adolescents was $9 \%$. This was lower than the prevalence of cigarette consumption among Iranian adults (14.38\%) [70], and among college students (23.8\%) [71], as reported in the existing scholarly literature. Compared to international studies, our results are lower than those found in studies conducted in Saudi Arabia (19.5\%) [72], India (11.8\%) [73], Sudan (13.6\%) [74] and Italy (35.6\%) [75] and higher than the prevalence computed in studies carried out in Ethiopia (3\%) [76] and China (7.93\%) [77]. Our estimates were similar to the results of a metaanalysis conducted in East Africa (9.02\%) [78]. The prevalence of former smoking behavior among Iranian adolescents was estimated to be $24 \%$. This rate was lower than the findings of studies carried out in Mexico (29.6\%) [79] and Nigeria (32\%) [80] but higher than the findings of a study performed in Turkey (12\%) [81].

This difference in prevalence across studies can be due to social, cultural, health conditions, and legal factors [72, 74, 75, 78]. Different study settings could explain the variability of the findings: some studies were done in schools and teachers were present when the data were collected. This could have affected the reliability of the replies [75].

Both current and former smoking behavior was higher in boys than in girls $[2,5,8,9,13]$. Men are more at risk of exposure to cigarettes and other health problems due to social conditions, curiosity, propensity to experiencing high-risk situations, and the pressures they face [72]. In 


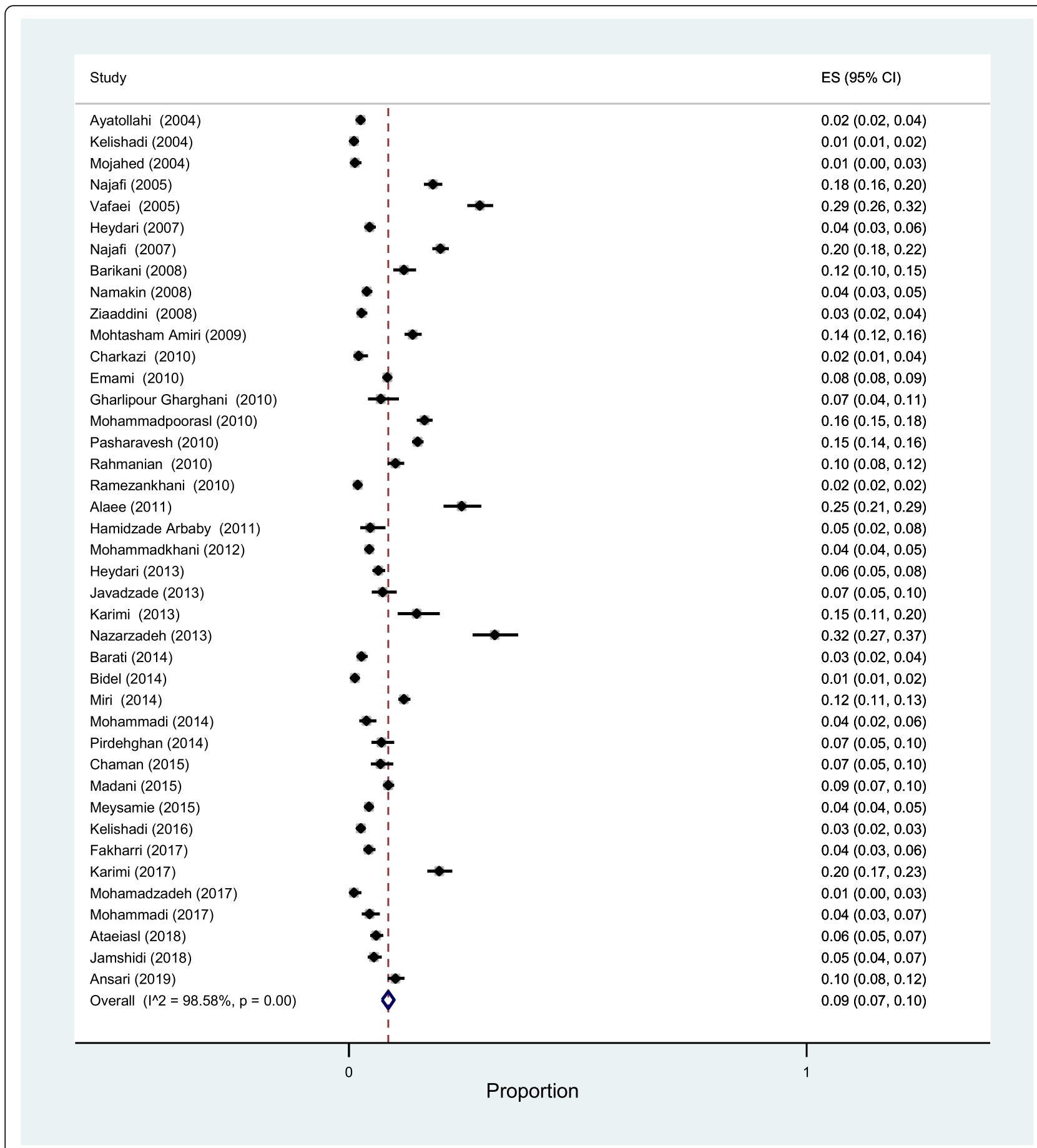

Fig. 2 The forest plot of the studies included in the present systematic review and meta-analysis investigating the prevalence of current smoking behavior among Iranian adolescents using the random-effect model

boys, the risk of smoking increases with parents (especially fathers) smoking. Parental education is, as such, very important. Women tend to smoke less because of personality traits [82] as well as, especially in countries like Iran, for cultural reasons and stigma. Unfortunately, adolescent boys, due to the high influence of their friends, see smoking as a sign of adulthood, and their lack of awareness and education has made them more likely to smoke than adolescent girls [74, 80, 81].

The results of the analysis based on geographical areas showed that the highest prevalence was in the north (13\%) and east (10\%), even though this should be interpreted only 

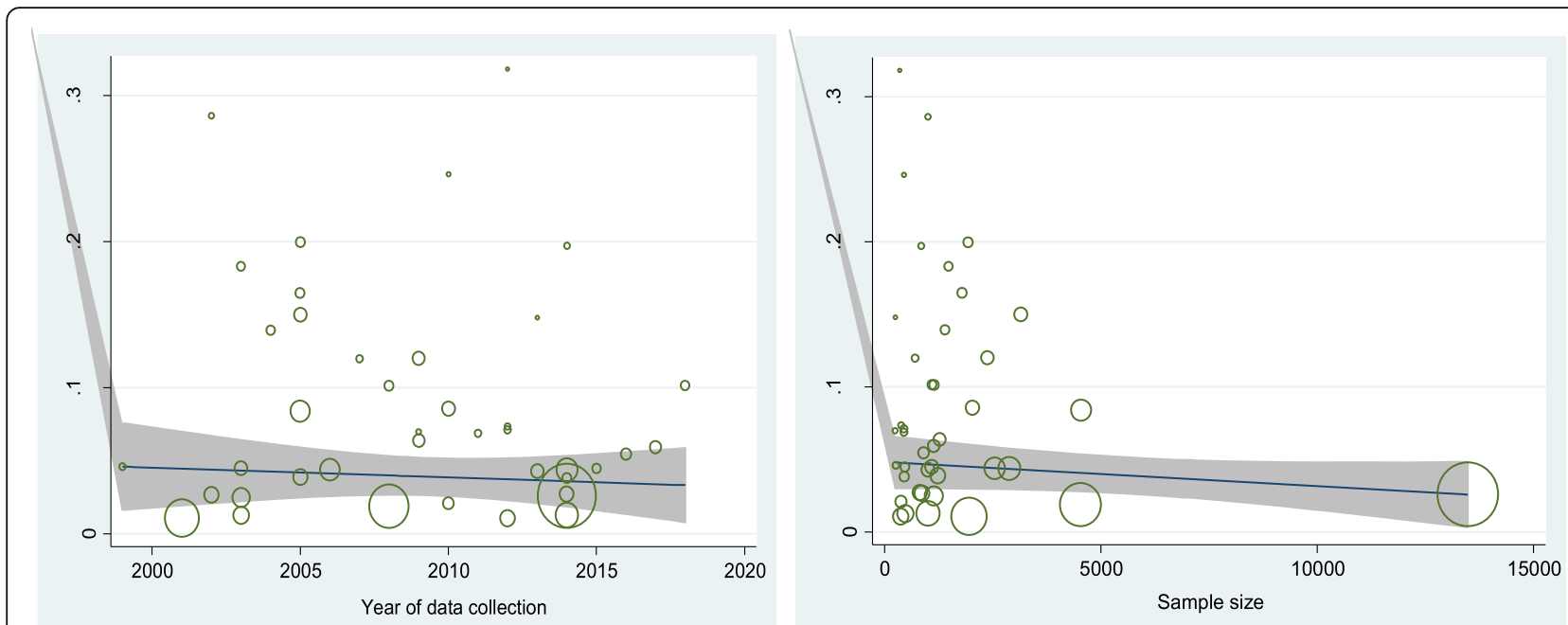

Fig. 3 Results of meta-regression analysis based on the year of data collection and sample size of the included studies of current smoking behavior among Iranian adolescents

as a trend, given the absence of statistical significance. In the northern parts of Iran, drug use is, indeed, of great concern, and the high prevalence of drug use among parents and adolescents has made them more likely to smoke [83]. The eastern part of Iran is bordered by Afghanistan and Pakistan and, therefore, the high prevalence of narcotics in these two countries has led to a higher volume of cigarette consumption and drug use in these provinces. According to adolescents, these areas are among those with the highest prevalence of cigarette consumption in Iran [84].

Result of meta-regression according to the year of data collection in current adolescent smokers show a marked increase, although not statistically significant, but this increase can be considered as an important signal for health policy- and decision-makers. On the other hand, in recent decades, one of the factors affecting the behavior of adolescents in Iran and elsewhere in the world is the increasing access to virtual and internet networks. By creating new patterns of behaviors, these networks have induced people to adopt new lifestyles, which also

Table 3 Sub-group analyses based on gender and publication year for current smokers among Iranian adolescents

\begin{tabular}{lllll}
\hline Gender & Time Period (year) & Prevalence $(95 \% \mathrm{Cl})$ & $\mathrm{I}^{2}$ & $P$-value \\
\hline Male & $2000-2005$ & $10 \%(2$ to 19$)$ & $98.74 \%$ & 0.38 \\
& $2006-2010$ & $10 \%(6$ to 15$)$ & $98.73 \%$ & 0.12 \\
& $2011-2015$ & $11 \%(8$ to 15$)$ & $97.82 \%$ & 0.72 \\
& $2016-2019$ & $19 \%(8$ to 31$)$ & $99.53 \%$ & 0.46 \\
Female & $2000-2005$ & $5 \%(4$ to 13$)$ & $98.6 \%$ & 0.19 \\
& $2006-2010$ & $7 \%(4$ to 11$)$ & $99.13 \%$ & 0.52 \\
& $2011-2015$ & $5 \%(2$ to 7$)$ & $94.73 \%$ & 0.82 \\
& $2016-2019$ & $6 \%(3$ to 8$)$ & $98.63 \%$ & 0.28 \\
\hline
\end{tabular}

include appropriate programs to deal with and prevent risk factors [85].

Factors affecting smoking behavior in adolescents in Iran In the studies selected, various factors were found to be associated with smoking behavior, such as the presence of a smoker in the family, a lack of awareness of the consequences of smoking, easy access to cigarettes, and the lack of governmental laws to sell them to adolescents. Deaths of family members, parents, gender, smoking friends, dissatisfaction with family, highly emotional environment, divorce, family disputes, history of school and family escape, curiosity about smoking experience, social problems, low parental education level and low family economic level were other significant determinants of smoking behavior (Appendix 3).

According to most studies, smoking was mentioned as a common habit because of its cheapness, convenience and affordability. In Iran, there are no smoking rules for people under the age of 18 , in terms of rules prohibiting shops to sell them to this age group. The problem with this is the lack of control over these stores, and teens can easily buy and consume cigarettes. The low price of cigarettes in Iran has made adolescents not having a particular problem in buying cigarettes. Restrictions on access, price hikes, and stricter laws are effective in preventing and controlling smoking behavior among adolescents and should be addressed by health policy- and decision-makers. There was a significant relationship between the decrease in smoking and the increase in its price, with some adolescents being unable to afford the costs of purchasing cigarettes. Adopting rules to limit smoking in teens is expected to slow down the process of smoking [86]. 


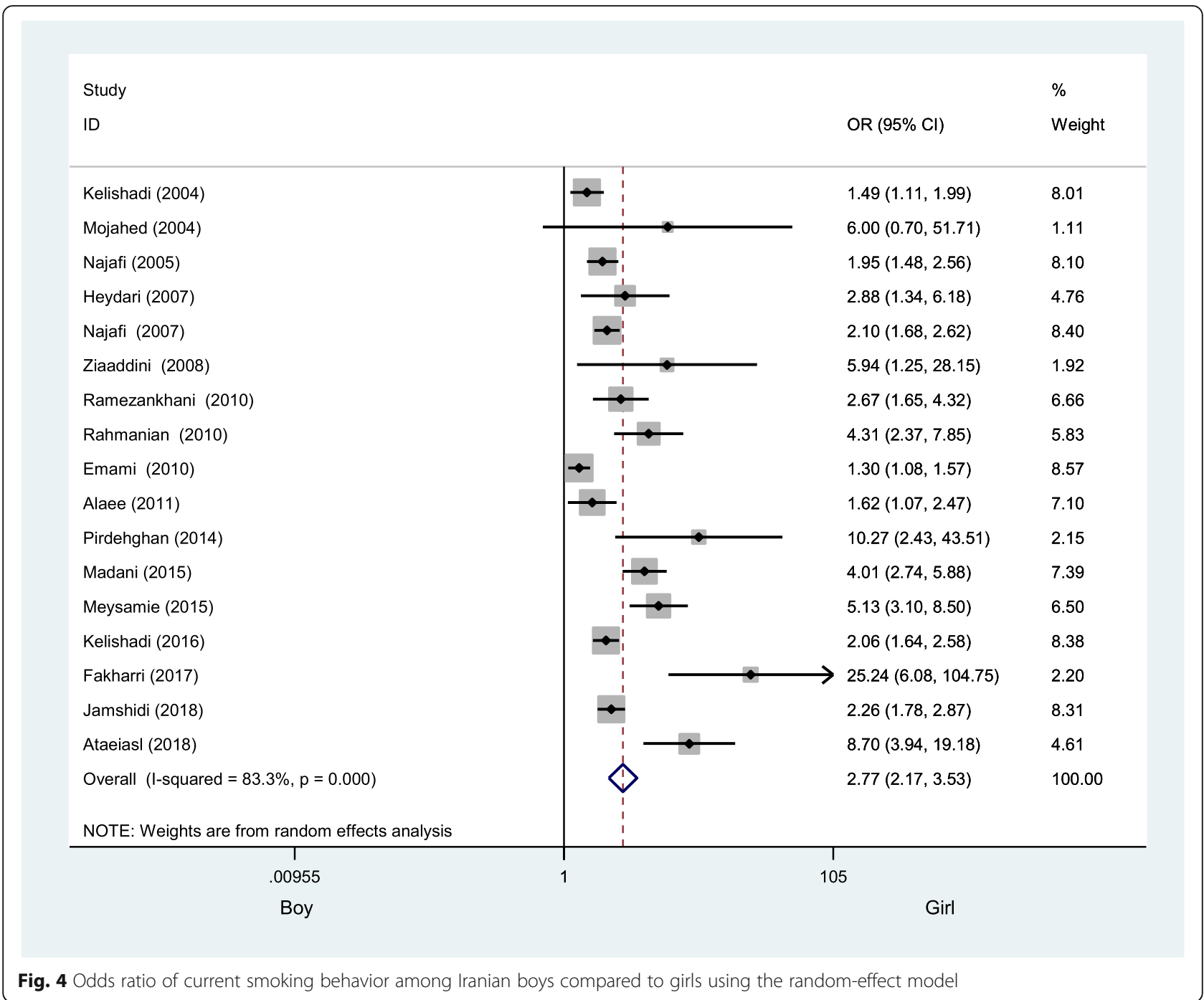

Table 4 Prevalence rate of current smoking behavior stratified according to geographical area and tool used

\begin{tabular}{lll}
\hline Variable & Prevalence $95 \% \mathrm{Cl}$ & $\mathrm{I}^{2}$ \\
\hline Tools & & \\
GYTP & $7 \%(1$ to 13$)$ & $99.25 \%$ \\
MCMI-III & $4 \%(3$ to 6( & - \\
GSHS & $3 \%(2$ to 3$)$ & - \\
SRG & $9 \%(7$ to 11$)$ & $98.48 \%$ \\
Geographical area & & \\
Central & $7 \%(5$ to 9$)$ & $97.47 \%$ \\
East & $10 \%(6$ to 13$)$ & $97.73 \%$ \\
North & $13 \%(7$ to 18$)$ & $98.48 \%$ \\
South & $8 \%(5$ to 11$)$ & $88.82 \%$ \\
West & $8 \%(4$ to 12$)$ & $98.97 \%$ \\
\hline
\end{tabular}

Basically, smoking in Iranian society is not wellperceived because of religious and cultural issues, and there is a negative attitude towards smokers (especially women). People cannot smoke in public environments such as schools and universities. Religious issues can be widely used for prevention and control tobacco in Iran. In some selected studies, adolescents with stronger religious beliefs were less likely to smoke. Parental education is another valid strategy in that many families have been able to prevent smoking behavior among their children by raising their awareness of the consequences of being exposed to cigarette smoke [87]. Therefore, the role of religion as a deterrent to high-risk behaviors in adolescents should be considered [88] as well as the role of parental education.

Another factor contributing to the increase in cigarette consumption is their social attractiveness and availability in the market (such as, various forms of cigarettes with 


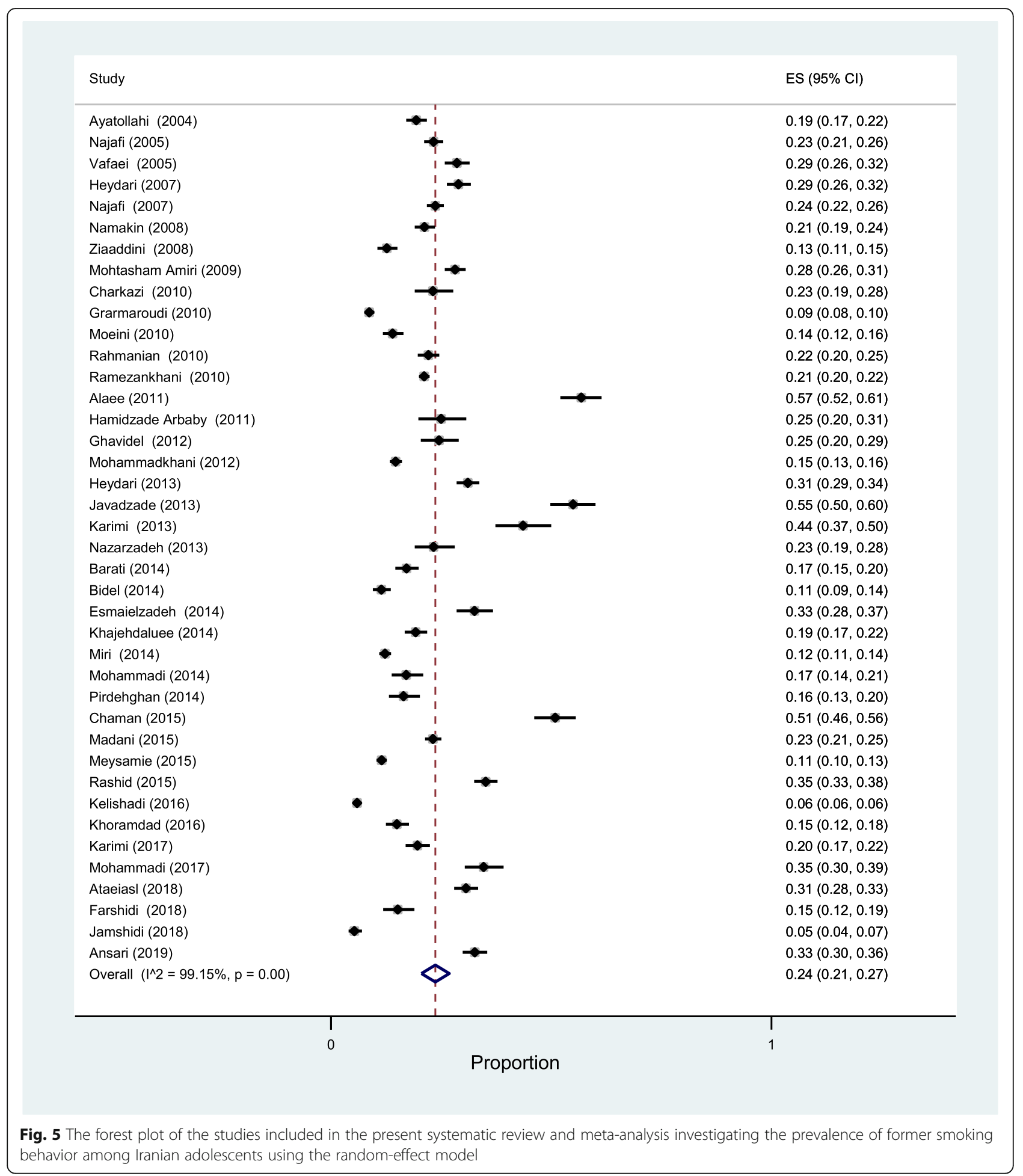

different shapes and colors, attractive flavors and envelopes, showing attractive scenes of popular young actors and actresses consuming them). According to some studies, the attractiveness of smoking and its widespread advertising in the stores have led teens to try to smoke as a new experience. In recent years, Iranian laws have banned smoking scenes on television, and this tobacco control policy has been very useful for prevention, even if partially.

Family disputes, divorce, and parental neglect on behaviors that put adolescents at risk have been mentioned as smoking determinants in many studies. Personality 


\begin{tabular}{|c|c|}
\hline \multirow{2}{*}{$\begin{array}{l}\text { Study } \\
\text { ID }\end{array}$} & $\%$ \\
\hline & Weight \\
\hline Najafi (2005) & 5.86 \\
\hline Heydari (2007) & 5.73 \\
\hline Najafi (2007) & 5.88 \\
\hline Ziaaddini (2008) & 4.12 \\
\hline Ramezankhani (2010) & 6.25 \\
\hline Rahmanian (2010) & 3.82 \\
\hline Grarmaroudi (2010) & 5.55 \\
\hline Alaee (2011) & 5.52 \\
\hline Mohammadkhani (2012) & 5.87 \\
\hline Pirdehghan (2014) & 4.30 \\
\hline Khajehdaluee (2014) & 5.39 \\
\hline Madani (2015) & 5.11 \\
\hline Meysamie (2015) & 5.96 \\
\hline Rashid (2015) & 5.86 \\
\hline Kelishadi (2016) & 6.22 \\
\hline Mohammadi (2017) & 4.59 \\
\hline Jamshidi (2018) & 3.96 \\
\hline Ataeiasl (2018) & 5.45 \\
\hline Ansari (2019) & 4.56 \\
\hline Overall (I-squared $=88.1 \%, p=0.000)$ & 100.00 \\
\hline NOTE: Weights are from random effects analysis & \\
\hline $\begin{array}{c} \\
117 \\
.\end{array}$ & \\
\hline Boy & \\
\hline
\end{tabular}

Table 5 Sub-group analyses based on gender and publication year for former smokers among Iranian adolescents

\begin{tabular}{lllll}
\hline Gender & Time Period (year) & Prevalence Rate $(95 \%$ Cl) & $1^{2}$ & P-value \\
\hline Male & $2000-2005$ & $32 \%(7$ to 68$)$ & $99.32 \%$ & 0.61 \\
& $2006-2010$ & $21 \%(15$ to 26$)$ & $98.01 \%$ & 0.35 \\
& $2011-2015$ & $29 \%(23$ to 36$)$ & $98.62 \%$ & 0.24 \\
& $2016-2019$ & $17 \%(11$ to 23$)$ & $98.87 \%$ & 0.18 \\
Female & $2000-2005$ & $14 \%(12$ to 17$)$ & - & 0.16 \\
& $2006-2010$ & $11 \%(6$ to 17$)$ & $97.90 \%$ & 0.57 \\
& $2011-2015$ & $18 \%(11$ to 24$)$ & $98.43 \%$ & 0.48 \\
& $2016-2019$ & $7 \%(4$ to 10$)$ & $91.82 \%$ & 0.71 \\
\hline
\end{tabular}

traits are also another crucial factor of smoking: anxiety, willingness to take risky behaviors [89] as well as curiosity and the tendency for new emotions and experiences. Many people smoke cigarettes because of their inability to manage their negative emotions and to avoid problems and stressors. The instant relaxation of a cigarette encourages cigarette consumption over time. In these people knowledge of emotion control skills and stress reduction strategies are very useful in preventing or, at least, reducing smoking behavior [78].

Moreover, family plays an important role in shaping adolescents' personality, building confidence, feeling secure, and behaving in a more proactive manner. Sufficient support, attention, and sensitivity of parents can help a person adapt better to the environment, coping with problems, increasing social skills and reducing the risk of unhealthy behaviors. On the other hand, family can 

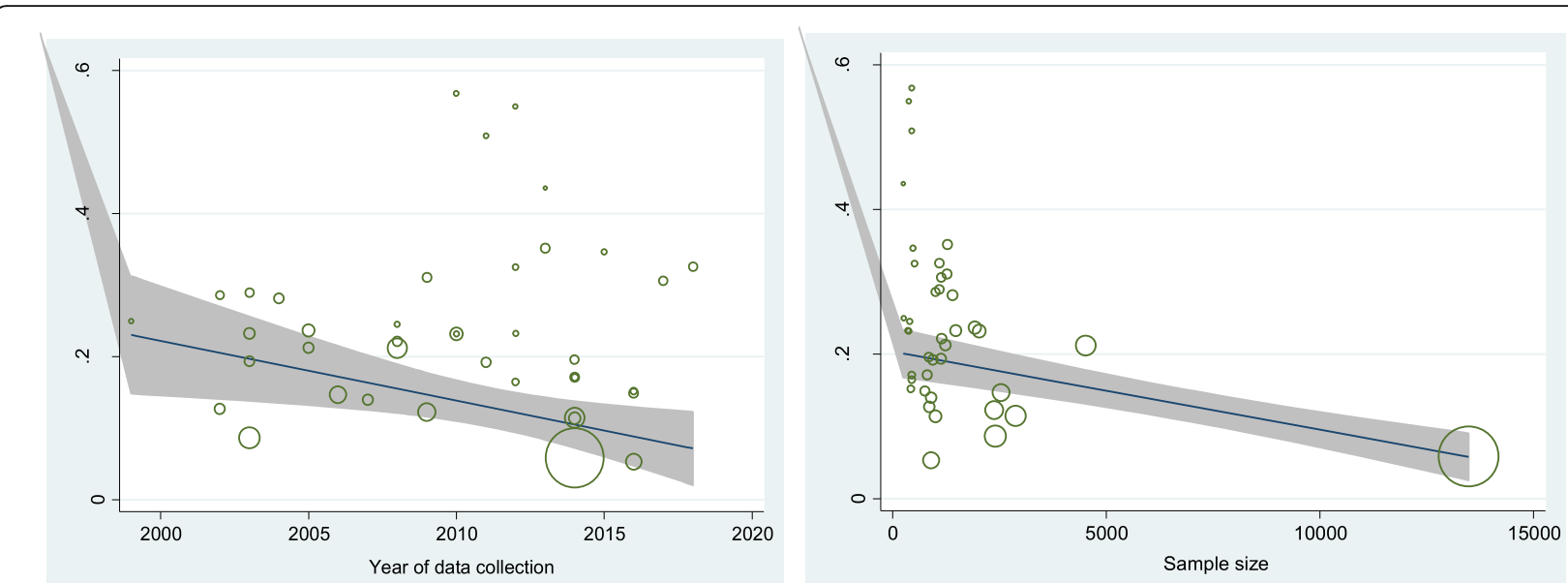

Fig. 7 Results of meta-regression analysis based on the year of data collection and sample size of the included studies of former smoking behavior among Iranian adolescents

make the adolescent feel safe or vice versa, cause him or her to develop psychological issues $[88,90]$. The more parents ignore the youth, the more vulnerable they are to the environment and society. Young people in poorly supportive families are more likely to experience anxiety, depression, low self-esteem and self-efficacy, and problems in relationships, as well as various educational and social failures. In these situations, people are more likely to resort to smoking, alcohol, or drugs to get rid of their problems. In addition, parents are the most effective example in terms of behavioral patterns for their children [73].

The impact of friends and peers in terms of adoption of particular attitudes and behaviors such as the tendency to smoke was also highly emphasized in many studies. Many people start smoking imitating their peers. Some adolescents can give up on their requests and wishes, because they want to be in touch with their friends and peers, since it is so important to be accepted by friends during the periods of adolescence and young adulthood [72]. These behaviors can be exacerbated when one wants to define their identity by communicating with their favorite friendship group. Under these circumstances, peers are more likely to be accepted if smoking [91].

Furthermore, in most studies included in the present systematic review and meta-analysis, many adolescents did not know much about the effects of smoking. They were not educated by their families and teachers about the consequences of being exposed to cigarette smoke. Although many health professionals regularly report on the harm of smoking, many people are unaware of the exact side effects of smoking [92]. Having information about the annual deaths from smoking and the number of people with lung, breast, skin, bladder cancers or other tumors caused by smoking can be more effective in preventing cigarette consumption. The lack of this information leads to the formation of false beliefs about smoking and to the fact that people do not take the effects of smoking seriously and think that severe illnesses such as cancers are rare [93].

Moreover, other factors influencing smoking behavior among adolescents in many of the studies selected were economic conditions and parental literacy. Families whose parents had a low economic level were more likely to smoke and this effect on adolescents' behaviors was particularly evident in some selected studies. In addition, adolescents whose parents had low literacy levels were more likely to smoke, which was consistent with findings from other studies carried out in various countries [74, 82, 92].

\section{Limitations}

This study has some limitations that may be mentioned. The high, statistically significant heterogeneity found is the major shortcoming. Further, countrywide studies conducted using standardized, validated questionnaires with a large sample size could not be found in the present systematic review and meta-analysis. This should be on the agenda of healthcare decision-, policy-makers and researchers for the future. Moreover, the study data collected were insufficient to investigate the relationship between smoking determinants and the prevalence of current/ former smoking behavior from a quantitative standpoint. As such, we could only perform a qualitative synthesis of tobacco-related predictors. Finally, in some provinces and regions of Iran, no studies have been conducted so far on the topic object of the present investigation.

\section{Conclusion}

The findings of this study showed that the prevalence of current smoking behavior among Iranian adolescent 
boys is rather high and has been increasing throughout the time, even though not in a statistically significant way. The country's young population should be given more attention by health policy- and decision-makers. Implementation of ad hoc prevention and control policies should be on their agenda. The cooperation of families and teachers plays a very important role with this regard. If these policies are not implemented, the Iranian health sector will face serious problems with the consequences of smoking. Raising awareness and providing appropriate conditions to reduce risky behaviors among adolescents can greatly prevent their propensity to smoke.

\section{Appendix 1}

Figure 8 The prevalence of current smokers according to gender among adolescents aged $12-17$ years in Iran (boys, 1A, and girls, 1B). a The prevalence of current smokers among Iranian boys aged $12-17$ years. $\mathrm{b}$ The prevalence of current smokers among Iranian girls aged $12-17$ years

\section{Appendix 2}

Figure 9 The prevalence of former smoking behavior according to gender among adolescents aged $12-17$ years in Iran (2A, boys, and girls, 2B). a The prevalence of former smoking behavior among Iranian boys aged $12-$ 17 years. $\mathrm{b}$ The prevalence of former smoking behavior among Iranian girls aged $12-17$ years

\section{Appendix 3}

Table 6 Factors affecting smoking behavior according to the studies included in the present systematic review and meta-analysis

\begin{tabular}{lll}
\hline $\begin{array}{l}\text { Factors affecting smoking } \\
\text { behavior in included studies }\end{array}$ & $\begin{array}{l}\text { Number of } \\
\text { studies per } \\
\text { factor }\end{array}$ & $\begin{array}{l}\text { Number of } \\
\text { reporting a } \\
\text { strength of } \\
\text { significantly } \\
\text { smoking b }\end{array}$ \\
$\begin{array}{lll}\text { Smoker in the family } & 27(55.1 \%) & 8(29.6 \%)\end{array}$ \\
$\begin{array}{l}\text { Lack of awareness of the } \\
\text { consequences of smoking }\end{array}$ & $16(32.7 \%)$ & $5(31.3 \%)$ \\
Easy access to cigarettes & $14(28.6 \%)$ & $4(28.6 \%)$ \\
$\begin{array}{l}\text { The lack of governmental } \\
\text { laws to sell cigarettes to }\end{array}$ & $3(6.1 \%)$ & $0(0.0 \%)$ \\
adolescents & $9(18.4 \%)$ & $6(66.7 \%)$ \\
Deaths of family members & $23(46.9 \%)$ & $15(65.2 \%)$ \\
Gender & $17(34.7 \%)$ & $13(76.5 \%)$ \\
Smoking friends & $11(22.4 \%)$ & $6(54.5 \%)$ \\
Dissatisfaction with family & $8(16.3 \%)$ & $3(37.5 \%)$ \\
Highly emotional & & $2(40.0 \%)$ \\
environment & $12(24.5 \%)$ & $7(58.3 \%)$ \\
Divorce & & \\
Family disputes & &
\end{tabular}

\section{Appendix 3 (Continued)}

\begin{tabular}{lll}
\hline $\begin{array}{l}\text { History of school and family } \\
\text { escape }\end{array}$ & $3(6.1 \%)$ & $1(33.3 \%)$ \\
$\begin{array}{l}\text { Curiosity about smoking } \\
\text { experience }\end{array}$ & $9(18.4 \%)$ & $6(66.7 \%)$ \\
$\begin{array}{l}\text { Social problems } \\
\text { Low parental education }\end{array}$ & $10(20.4 \%)$ & $4(40.0 \%)$ \\
level & $2(28.6 \%)$ \\
Low family economic level & $15(30.6 \%)$ & $2(13.3 \%)$ \\
\hline
\end{tabular}

\section{Abbreviations}

Cl: Confidence interval; JBI: Joanna Briggs Institute; PRISMA: Preferred Reporting Items for Systematic Reviews and Meta-Analyses; SID: Scientific Information Database; WHO: World Health Organization

\section{Acknowledgements}

Not applicable.

\section{Authors' contributions}

EEC, MaB, MeB and HSS conceived and designed the study. MaBe, MA and MeB searched databases, extracted data and performed the studies selection. HSS, AB NLB, EEC and MaB interpreted the results. MaB, MeB, AB and NLB performed the data analysis. All authors edited and revised the paper. All authors read and approved the final paper for publication.

Funding

This study was supported by the Tehran University of Medical Sciences.

Availability of data and materials

Not applicable.

Ethics approval and consent to participate

Not applicable.

Consent for publication

Not applicable.

\section{Competing interests}

The authors declare that they have no competing interests.

\section{Author details}

${ }^{1}$ National Institute for Health Research, Tehran University of Medical Sciences, Tehran, Iran. ${ }^{2}$ Health Management and Economics Research Center, Iran University of Medical Sciences, Tehran, Iran. ${ }^{3}$ Department of Medicine, School of Medicine, Iran University of Medical Science, Tehran, Iran. ${ }^{4}$ Social Determinants of Health Research Center, Lorestan University of Medical Sciences, Khorramabad, Iran. ${ }^{5}$ Department of Health Sciences (DISSAL), Postgraduate School of Public Health, University of Genoa, Genoa, Italy. ${ }^{6}$ Department of Mathematics and Statistics, Laboratory for Industrial and Applied Mathematics (LIAM), York University, Toronto, Canada.

Received: 3 December 2019 Accepted: 21 January 2020 Published online: 31 January 2020

\section{References}

1. Allen SI, Foulds J, Wasserman E, Veldheer S, Hrabovsky S, Yingst J, et al. Tobacco use among middle and high school students in Pennsylvania. Prev Chronic Dis. 2018;15:E19.

2. Rudatsikira E, Muula AS, Siziya S. Current cigarette smoking among in-school American youth: results from the 2004 national youth tobacco survey. Int J Equity Health. 2009;8:10.

3. Jacob L, Freyn M, Kalder M, Dinas K, Kostev K. Impact of tobacco smoking on the risk of developing 25 different cancers in the UK: a retrospective study of 422,010 patients followed for up to 30 years. Oncotarget. 2018; 9(25):17420-9. 
4. Lim SS, Vos T, Flaxman AD, Danaei G, Shibuya K, Adair-Rohani H, et al. A comparative risk assessment of burden of disease and injury attributable to 67 risk factors and risk factor clusters in 21 regions, 1990-2010: a systematic analysis for the global burden of disease study 2010. Lancet. 2012;380(9859): 2224-60.

5. Mbongwe B, Tapera R, Phaladze N, Lord A, Zetola NM. Predictors of smoking among primary and secondary school students in Botswana. PLoS One. 2017;12(4):e0175640.

6. Muula AS, Mpabulungi L. Cigarette smoking prevalence among schoolgoing adolescents in two African capital cities: Kampala Uganda and Lilongwe Malawi. Afr Health Sci. 2007;7(1):45-9.

7. World Health Organization. Tobacco,Key facts 2019 [Available from: https:// www.who.int/news-room/fact-sheets/detail/tobacco.

8. Dearden KA, Crookston BT, De La Cruz NG, Lindsay GB, Bowden A, Carlston $\mathrm{L}$, et al. Teens in trouble: cigarette use and risky behaviors among private, high school students in La Paz. Bolivia Rev Panam Salud Publica. 2007;22(3):160-8.

9. White HR, Violette NM, Metzger L, Stouthamer-Loeber M. Adolescent risk factors for late-onset smoking among African American young men. Nicotine Tob Res. 2007;9(1):153-61.

10. Aras S, Semin S, Gunay T, Orcin E, Ozan S. Sexual attitudes and risk-taking behaviors of high school students in Turkey. J Sch Health. 2007;77(7):359-66.

11. Faeh D, Viswanathan B, Chiolero A, Warren W, Bovet P. Clustering of smoking, alcohol drinking and cannabis use in adolescents in a rapidly developing country. BMC Public Health. 2006:6:169.

12. Reda AA, Moges A, Yazew B, Biadgilign S. Determinants of cigarette smoking among school adolescents in eastern Ethiopia: a cross-sectional study. Harm Reduct J. 2012;9:39.

13. Hesketh T, Ding QJ, Tomkins A. Smoking among youths in China. Am J Public Health. 2001;9(10):1653-5.

14. Han J, Chen X. A meta-analysis of cigarette smoking prevalence among adolescents in China: 1981-2010. Int J Environ Res Public Healt. 2015;12(5): 4617-30.

15. Munn Z, Moola S, Lisy K, Riitano D, Tufanaru C. Methodological guidance for systematic reviews of observational epidemiological studies reporting prevalence and cumulative incidence data. Int J Evid Based Healthc. 2015; 13(3):147-53.

16. Viera AJ, Garrett JM. Understanding interobserver agreement: the kappa statistic. Fam Med. 2005;37(3):360-3.

17. DerSimonian R, Laird N. Meta-analysis in clinical trials. Control Clin Trials. 1986;7(3):177-88.

18. Higgins JP, Thompson SG, Deeks JJ, Altman DG. Measuring inconsistency in meta-analyses. BMJ. 2003;327(7414):557-60.

19. Egger M, Davey Smith G, Schneider M, Minder C. Bias in meta-analysis detected by a simple, graphical test. BMJ. 1997;315(7109):629-34.

20. Moher D, Liberati A, Tetzlaff J, Altman DG, PRISMA Group. Preferred reporting items for systematic reviews and meta-analyses: the PRISMA statement. PLoS Med. 2009;6(7):e1000097.

21. Ayatollahi SA, Mohammadpoorasl A, Rajaeefard A. Predicting three stages of smoking acquisition in the male students of Shiraz high schools. Tabriz Uni Med Sci Health Sci. 2004:26(4):1-6.

22. Kelishadi R, Hashemi poor M, Sarraf zadegan N, Sadri GH, Bashar doost N, Alikhasi $\mathrm{H}$, et al. Effects of some environmental factors on smoking and the consequences of smoking on major cardiovascular disease (CVD) risk factors in adolescent: Isfahan healthy heart program- heart health promotion from childhood. J Guilan Uni Med Sci. 2004;13(50):62-75.

23. Mojahed A, Bakhshani NM. Prevalence of smoking and drug abuse in students of Zahedan high schools. Zahedan J Res Med Sci. 2004;6(1):e95038.

24. Najafi K. The prevalence of substance use among high-school students in Rasht City (Iran). IJPCP. 2005;11(2):233-6.

25. Vafaei B, Shaham FJ. Effective factors in tendency towards cigarette smoking among Tabrizian high school students. J Babol Uni Med Sci. 2005; 7(1):57-62.

26. Heydari G, Sharifi H, Hosseini M, Masjedi MR. Prevalence of smoking among high-school students of Tehran in 2003. East Mediterr Health J. 2007;13(5): 1017-21.

27. Najafi K, Fekri F, Mohseni R, Zarrabi H, Nazifi F, Faghir Pour M, et al. Survey of the prevalence of substance use among high school students in Guilan 2005-2006. J Guilan Uni Med Sci. 2007;16(62):67-79.

28. Barikani A. High risk behaviors in adolescent students in Tehran. IJPCP. 2008; 14(2):192-8
29. Namakin K, Sharifzadeh G, Miri M. Prevalence of cigarette smoking and evaluation of attitude and knowledge in its high school boys in Birjand, 2005. J Birjand Univ Med Sci. 2008;15:1.

30. Ziaaddini $\mathrm{H}$. Prevalence of cigarette smoking and relevant factors among school students in south of Iran. 2008;10(39):239-45.

31. Mohtasham Amiri Z, Cirus Bakht S, Nikravesh rad S. Cigarette smoking among male high school students in Rasht. J Guilan Uni Med Sci. 2009; 17(65):100-7.

32. Charkazi A, Rakhshani F, Esmaeili A, Esmaeili AJ. Eleventh grade student's attitude based on health belief model (hbm) toward smoking and it's complications in Zahedan. J Res Dev Nurs Midw. 2010;7(2):49-57.

33. Emami H, Naseri-Kouzehgarani G, Saeedfar K, Rezai Shiraz A, Masjedi M. The correlation of student's smoking and their perceived exposure to their teacher's smoking in Tehran: a population based study. J Shaheed Sadoughi Uni Med Sci. 2010;18(2):98-110.

34. Gharlipour Gharghani Z, Hazavehei MM, Sharifi MH, Nazari M. Study of cigarette smoking status using extended parallel process model(EPPM) among secondary school male students in Shiraz city. Jentashapir J Health Res. 2010;2(2):26-36.

35. Grarmaroudi GR, Makarem J, Alavi SS, Abbasi Z. Health related risk behaviors among high school students in Tehran. Iran Payesh. 2010;9(1):13-9.

36. Moeini $B$, Allahverdipour $\mathrm{H}$. Cigarette use and its predicting factors among male high school students. J Urmia Nurs Midwifery Fac. 2010;8(4).

37. Mohammadpoorasl A, Fakhari A, Rostami F, Shamsipour M. Survey of transition in different stages of cigarette smoking and its personal environmental factors in adolescents. Iran J Epidemiol. 2010;5(4):1-7.

38. Pasharavesh L, Khoshbo S, Rezaei M, Saiedi MR. Frequency and related factors of smoking in high school girls in Kermanshah (2004). J Kermanshah Univ Med Sci. 2010;13(4):e79583.

39. Rahmanian K, Jafarzadeh A, Khalooei A. Determinants of smoking behavior among high school students in Jahrom. Payavard. 2010;4(2 and 1):1-2.

40. Ramezankhani A, Sarbandizaboli F, Zarghi A, Heidari G, Masjedi M. Pattern of cigarette smoking in adolescent students in Tehran. Pajoohande. 2010;15(3):115-22.

41. Alaee R, Kadivar P, Mohammadkhani S, Sarami G, Alaee S. The prevalence of tobacco, Hubble-bubble, alcoholic drinks, drugs, and stimulants among high-school students. J Res Addict. 2011;18(5):1-16.

42. Hamidzade AY. Prevalence of smokers among high school students in Khalkhal city. J Res Health Sci. 2011;1(1):49-55.

43. Ghavidel N, Samadi M, Kharmanbiz A, Asadi A, Feyzi A, Ahmadi R, et al. Investigation of substance use prevalence and the interrelated factors involved through third-year high school students in Nazarabad city from January 2008 to June 2008. Razi J Med Sci. 2012;19(97):29-37.

44. Mohammadkhani S. Prevalence of cigarette smoking, alcohol drinking and illegal drugs use among Iranian adolescents. J Kerman Uni Med Sci. 2012; 19(1):32-48.

45. Heydari G, Yousefifard M, Hosseini M, Ramezankhani A, Masjedi MR. Cigarette smoking, knowledge, attitude and prediction of smoking between male students, teachers and clergymen in Tehran, Iran, 2009. Int J Prev Med. 2013;4(5):557-64.

46. Javadzade $\mathrm{SH}$, Shahnazi H, Sharifirad G, Reisi M, Tavassoli E. The status of knowledge and belief of pre-university male students in Isfahan, Iran, on smoking and its harmful effects and the prevalence of smoking among them. Health Syst Res. 2013;9(6):587-93.

47. Karimi M, Niknami S, Heydarnia AR, Hajizdeh E, Shamsi M. Predicting smoking among adolescents: examining the role of smoking self-identity in the theory of planned behavior. Health Syst Res. 2013;9(3):301-11.

48. Nazarzadeh M, Bidel Z, Ayubi E, Bahrami A, Tezval J, Rahimi M, et al. A survey of smoking prevalence and related risk factors among Zanjan students in 2011-2012. J Adv Med Biomed Res. 2013;21(84): $111-24$.

49. Barati M, Niknami S, Hidarnia A, Allahverdipour H. Predictors of tobacco smoking in male adolescents in Hamadan based on the theory of planned behavior. J Educ Community Health. 2014;1(3):28-37.

50. Bidel Z, Nazarzadeh M, Mohamadi MA, Zareeimanesh E, J T, Mohamadi E, et al. Smoking stages, prevalence of drug abuse and role of associated psychological and social factors: a study on male high school students in llam city. J Kerman Uni Med Sci. 2014:20(1):80-93.

51. Esmaielzadeh $\mathrm{H}$, Asadi M, Miri N, Keramatkar M. Prevalence of high risk behaviors among high school students of Qazvin in 2012. Iran J Epidemiol. 2014;10(3):75-82. 
52. Khajehdaluee M, Zavar A, Alidoust M, Pourandi R. Smoking among high school students of an area with medium socioeconomic status. J Pak Med Assoc. 2014;64(3):291-5.

53. Miri M, Ramazani A, Sharifzadeh G, Bahlgerdi M. Smoking and its correlates in male students in South Khorasan in 2008. Iran J Epidemiol. 2014;9(4):48-55.

54. Mohammadi F, Zakarianejad M, Valizadeh F. Determinants of smoking behavior among male high school students in Babolsar. Iran J Mazandaran Univ Med Sci. 2014;24(116):216-22.

55. Pirdehghan A, Vakili M, Arab M, Aghakoochak A. Smoking frequency and modeling the underlying predicting factors of tobacco smoking among high school students in Yazd city, 2012. J Shahrekord Univ Med Sci. 2014; 16(5):56-65.

56. Chaman R, Khosravi A, Sajedinejad S, Nazemi S, Fereidoon Mohasseli K, Valizade B, et al. Smoking and its related factors among Iranian high school students. Iran J Psychiatry Behav Sci. 2015;9(4):e1583.

57. Madani AH, Aghamolaei T, Madani M, Zarei F. Prevalence of smoking and associated internal and external factors in high school students in Bandar Abbas. Iran J Prev Med. 2015;2(4):40-9.

58. Meysamie A, Mahdiin Z, Seddigh L. Frequency of tobacco use among students in Tehran city. Tehran Univ Med J. 2015;73(7):515-26.

59. Rashid K. Epidemiology of high-risk behaviors among Tehran adolescent girls and boys. Soc Welf. 2015;15(57):31-55.

60. Kelishadi R, Shahsanai A, Qorbani M, Esmaeil Motlagh M, Jari M, Ardalan G, et al. Tobacco use and influencing factors among Iranian children and adolescents at national and subnational levels, according to socioeconomic status: the Caspian-IV study. Iran Red Crescent Med J. 2016;18(5):e21858.

61. Khoramdad M, Gholami F, Alimohamadi Y, Alavi Z, Shafiei J, Firouzi A. Prevalence of lifetime smoking and its determinant factors in high school adolescents in Shiraz. J Community Health Res. 2016:5(2):90-7.

62. Fakharri A, Jahani A, Sadeghi-Bazargani H, Farahbakhsh M, Asl AM Personality patterns and smoking behavior among students in Tabriz. Iran Electron Physician. 2017;9(3):3950-7.

63. Karimi M, Kaveh MH, Morowatisharifabad MA, Dehghani A, Dastjerdi G. Cigarette smoking experience and its related socio-demographic and environmental risk factors in high school boy students, Shiraz. Iran Int J Pediatr. 2017:5(2):4263-74.

64. Mohamadzadeh F, Peyman H, Sayemiri K, Soleiman Nezhad K. Evaluating the prevalence of cardiovascular risk factors in relation to demographical parameters among young adults in Ilam. J Ilam Uni Med Sci. 2017;25(3):201-12.

65. Mohammadi S, Ghajari H, Valizade R, Ghaderi N, Yousefi F, Taymoori P, et al. Predictors of smoking among the secondary high school boy students based on the health belief model. Int J Prev Med. 2017:8:24.

66. Ataeiasl M, Sarbakhsh P, Dadashzadeh H, Augner C, Anbarlouei M, Mohammadpoorasl A. Relationship between happiness and tobacco smoking among high school students. Epidemiol Health. 2018;40:e2018009.

67. Farshidi H, Aghamolaei T, Hosseini Z, Ghanbar Nejad A, Hosseini FA. Cigarette smoking based on prototype willingness model in male high school students. Int J High Risk Behav Addict. 2018;7(1):e63209.

68. Jamshidi F, Nazari N, Seyedian S, Mogahi S, Nabipour A, Dadgarinejad A, et al. Prevalence of smoking and related factors among high school students in Ahvaz city. Iran Asian J Pharm. 2018;12(3):S1094.

69. Ansari H, Khammarnia M, Okati H, Fakhrrahimi S, Mahdavifar N, Mohammadian $\mathrm{M}$, et al. The role of optimism in predicting tobacco smoking and illicit drug use among high school students in southeast of Iran, 2018. Health Scope. 2019;8(2):e89282.

70. Abdollahpour I, Mansournia MA, Salimi Y, Nedjat S. Lifetime prevalence and correlates of smoking behavior in Iranian adults' population; a crosssectional study. BMC Public Health. 2019;19(1):1056.

71. Panahi R, Tavousi M, Ramezankhani A, Sahraei M, Osmani F, et al. Smoking prevalence and its related factors among dormitory students of shahid beheshti university of medical sciences, Tehran. Iran Zahedan J Res Med Sci. 2018;20(8):e63037.

72. Algorinees RM, Alreshidi IG, Alateeq MF, Alghuraymi AA, Alfayez AA, FK A, et al. Prevalence of cigarette smoking usage among adolescent students in northern Saudi Arabia. Asian Pac J Cancer Prev. 2016;17(8):3839-43.

73. Thakur D, Gupta A, Thakur A, Mazta SR, Sharma D. Prevalence of cigarette smoking and its predictors among school going adolescents of North India. South Asian J Cancer. 2014;3(4):193-5.

74. Gadalla YM, Adil AM, Mustafa BM, Abdo H. Prevalence of smoking among school adolescents in Khartoum state. Sudan J Paediatr. 2012;12(2):44-8.
75. Panatto D, Amicizia D, Domnich A, Lai PA, Cristina ML, Signori A, et al Tobacco smoking among students in an urban area in northern Italy. J Prev Med Hyg. 2013;54(2):97-103.

76. Getachew S, Lewis S, Britton J, Deressa W, Fogarty AW. Prevalence and risk factors for initiating tobacco and alcohol consumption in adolescents living in urban and rural Ethiopia. Public Health. 2019;174:118-26.

77. Wang $M$, Zhong JM, Fang $L$, Wang $H$. Prevalence and associated factors of smoking in middle and high school students: a school-based cross-sectional study in Zhejiang Province. China BMJ Open. 2016;6(1):e010379.

78. Tezera N, Endalamaw A. Current cigarette smoking and its predictors among school-going adolescents in East Africa: a systematic review and meta-analysis. Int J Pediatr. 2019;2019:4769820

79. Bird Y, Staines-Orozco H, Moraros J. Adolescents' smoking experiences, family structure, parental smoking and socio-economic status in Ciudad Juárez, Mexico. Int J Equity Health. 2016:15:29.

80. Gana GJ, Idris SH, Sabitu K, Oche MO, Abubakar AA, Nguku PM. Prevalence and perception of cigarette smoking among out of school adolescents in Birnin Kebbi, North-western Nigeria. Pan Afr Med J. 2018;30:304.

81. Kaya CA, Unalan PC. Factors associated with adolescents' smoking experience and staying tobacco free. Ment Health Fam Med. 2010;7(3):145-53.

82. Nketiah-Amponsah E, Afful-Mensah G, Ampaw S. Determinants of cigarette smoking and smoking intensity among adult males in Ghana. BMC Public Health. 2018;18(1):941.

83. Pourshams A, Khademi H, Malekshah AF, Islami F, Nouraei M, Sadjadi AR, et al. Cohort profile: the Golestan cohort study--a prospective study of oesophageal cancer in northern Iran. Int J Epidemiol. 2010;39(1):52-9.

84. Momtazi S, Rawson R. Substance abuse among Iranian high school students. Curr Opin Psychiatry. 2010;23(3):221-6.

85. Blok DJ, de Vlas SJ, van Empelen P, van Lenthe FJ. The role of smoking in social networks on smoking cessation and relapse among adults: a longitudinal study. Prev Med. 2017;99:105-10.

86. Alimohammadi M, Jafari-Mansoorian H, Hashemi SY, Momenabadi V, Ghasemi SM, Karimyan K. Review on the implementation of the Islamic Republic of Iran about tobacco control, based on MPOWER, in the framework convention on tobacco control by the World Health Organization. Addict Health. 2017;9(3):183-9.

87. Allahverdipour H, Abbasi-Ghahramanloo A, Mohammadpoorasl A, Nowzari P. Cigarette smoking and its relationship with perceived familial support and religiosity of university students in Tabriz. Iran J Psychiatry. 2015;10(3): 136-43.

88. Brown QL, Linton SL, Harrell PT, Mancha BE, Alexandre PK, et al. The influence of religious attendance on smoking. Subst Use Misuse. 2014;9(11): 1392-9.

89. McGee CE, Trigwell J, Fairclough SJ, Murphy RC, Porcellato L, Ussher M, et al. Influence of family and friend smoking on intentions to smoke and smoking-related attitudes and refusal self-efficacy among 9-10 year old children from deprived neighbourhoods: a cross-sectional study. BMC Public Health. 2015:15:225.

90. Kang SY, Lee JA, Cho HJ. Trends in the ease of cigarette purchase among Korean adolescents: evidence from the Korea youth risk behavior webbased survey 2005-2016. BMC Public Health. 2018;18(1):1242.

91. Joung MJ, Han MA, Park J, Ryu SY. Association between family and friend smoking status and adolescent smoking behavior and e-cigarette use in Korea. Int J Environ Res Public Health. 2016;13(12):pii: E1183.

92. Agaku IT, Filippidis FT. Prevalence, determinants and impact of unawareness about the health consequences of tobacco use among 17,929 school personnel in 29 African countries. BMJ Open. 2014:4(8):e005837.

93. Ashraf Nazir M, Almas K. Awareness about the effects of tobacco consumption on oral health and the possibility of smoking behavior among male Saudi schoolchildren. Eur J Dent. 2017;11(1):29-35.

\section{Publisher's Note}

Springer Nature remains neutral with regard to jurisdictional claims in published maps and institutional affiliations. 